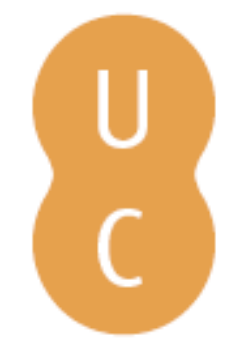

\title{
nommalina
}

\section{Dinâmicas(s) demográficas(s) nos municípios com áreas classificadas e o quadro vigente das estratégias nacionais de sustentabilidade do ambiente e do desenvolvimento: uma análise prospectiva}

\author{
Autor(es): Lopes, J. Cruz
}

Publicado por: Imprensa da Universidade de Coimbra

URL persistente:

URI:http://hdl.handle.net/10316.2/30760

DOI:

DOI:http://dx.doi.org/10.14195/978-989-26-0244-8_9

Accessed : $\quad$ 26-Apr-2023 08:45:38

A navegação consulta e descarregamento dos títulos inseridos nas Bibliotecas Digitais UC Digitalis, UC Pombalina e UC Impactum, pressupõem a aceitação plena e sem reservas dos Termos e Condições de Uso destas Bibliotecas Digitais, disponíveis em https://digitalis.uc.pt/pt-pt/termos.

Conforme exposto nos referidos Termos e Condições de Uso, o descarregamento de títulos de acesso restrito requer uma licença válida de autorização devendo o utilizador aceder ao(s) documento(s) a partir de um endereço de IP da instituição detentora da supramencionada licença.

Ao utilizador é apenas permitido o descarregamento para uso pessoal, pelo que o emprego do(s) título(s) descarregado(s) para outro fim, designadamente comercial, carece de autorização do respetivo autor ou editor da obra.

Na medida em que todas as obras da UC Digitalis se encontram protegidas pelo Código do Direito de Autor e Direitos Conexos e demais legislação aplicável, toda a cópia, parcial ou total, deste documento, nos casos em que é legalmente admitida, deverá conter ou fazer-se acompanhar por este aviso.

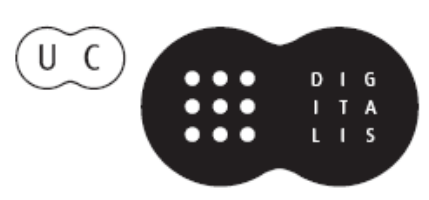




\section{TRUNFOS DE UMA}

\section{EOGRAFIA ACIVA}

\section{DESENVOLVIMENTO LOCAL,}

AMBIENTE,

ORDENAMENTO

E TECNOLOGIA

Norberto Santos

Lúcio Cunha

COORDENAÇÃO 
J. Cruz lopes

Instituto Politécnico de Viana do Castelo - ESTG

\author{
DINÂMICA(s) DEMOGRÁFICA(S) NOS MUNICÍPIOS COM ÁREAS CLASSIFICADAS E O \\ QUADRO VIGENTE DAS ESTRATÉGIAS NACIONAIS DE SUSTENTABILIDADE DO AMBIENTE E \\ DO DESENVOLVIMENTO. UMA ANÁLISE PROSPECTIVA
}

\title{
INTRODUÇÃO
}

No período de uma geração e tendo como limites os anos/dados censitários de 1970 e 2001 vários autores se têm debruçado sobre as mudanças sócio-territoriais e os processos de governação que lhe estão subjacentes. O território e a sociedade portuguesa conheceram profundas alteraçóes do seu padrão de composição, de dinâmicas de organização sócio-espacial e de complexas relaçóes, no seio da polis, entre o indivíduo e a comunidade, entre a comunidade local/regional e o poder instituído, entre as políticas nacionais e a evolução do quadro geopolítico das relaçóes multilaterais. A diversidade e a desigualdade são ainda traços marcantes da realidade portuguesa, a qual passou de uma sociedade dita dualista para uma sociedade qualificada como multipolar. As expressóes comuns de oposição e contrastes da realidade portuguesa - litoral versus interior, rural versus urbano perderam muito do seu significado inicial na transição do séc. XX para o actual. Em termos de qualificaçáo territorial e paisagística a realidade portuguesa passou a contar na década de setenta com a institucionalizaçáo de áreas protegidas, entendidas estas como unidades de conservação do nosso ambiente, submetidas a quadros técnico-legais de implementação e de funcionamento, em espaços que reúnem bens naturais e interesses culturais de valor nacional. A abordagem é uma visão evolutiva do quadro demográfico de um Portugal protegido, em oposição a um Portugal não protegido, em que os valores ambientais aí presentes irão sustentar as novas dinâmicas e tendências de estratégia do nosso desenvolvimento. Ora dos quatro cenários propostos pelo modelo do IPCC (2002), o que se configura como o mais desejável é o da «sustentabilidade comunitária» (Santos 2007), e esta é mais apropriada e viável nos espaços classificados de Portugal.

\section{TERritório Protegido: AS Áreas ProtegidAs (AP’s) CLASSIFICADAS}

No presente o universo das áreas classificadas do Continente está distribuído, ao nível do território concelhio, do seguinte modo: em quarenta e sete distribuem-se em menos de um terço da superfície municipal; catorze entre um terço e metade; oito entre metade e 
dois terços; uma em mais de dois terços; e duas em todo o espaço municipal (Manteigas e Marvão).

Nos estudos e âmbito da especialidade é recorrente considerar a criação da Reserva Ornitológica de Mindelo, em 11 Maio 1957, como o acto nacional inicial de criaçáo de um local com o conceito de «área protegida» em Portugal Continental. Reconhece-se, contudo, que a Lei no 9/70, de 19 de Junho, é a legislaçáo original que possibilita criar no território português áreas de protecção natural apropriadas, com fins de conservação do ambiente/natureza, e com a designação de Parque Nacional e outras categorias de Reservas Naturais (Figura 1). Em 5 de Outubro de 1970 processa-se um acontecimento oficial, através da visita do entáo Presidente da República ao Gerês e este aí ter descerrado uma lápide inaugural de (para a) criação do Parque Nacional da Peneda-Gerês (PNP-G), ao abrigo dessa recente legislação nacional. Só em Maio do ano seguinte é publicado o diploma legal da criaçáo oficial do PNP-G (Dec. no 187/71), com cerca de 600 quilómetros quadrados.

Figura 1 - Municípios com Áreas Classificadas (Parque Nacional e Reserva Natural).

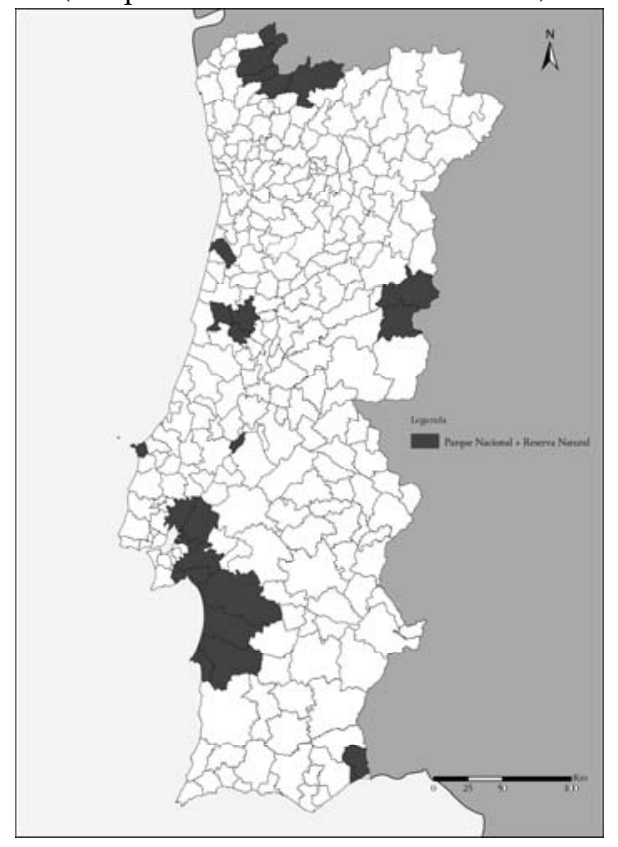

No contexto das mudanças políticas e sociais operadas em Portugal, em grande medida consagradas na Constituição democrática de 1976, o dispositivo técnico-legal vigente exigia um novo enquadramento orgânico e actualização funcional, pelo que o Decreto-Lei no 613/76, de 27 de Julho revoga a supracitada lei. Este cria uma nova categoria de AP Parque Natural - de génese europeia (Figura 2) - e passa também a existir a figura territorial de Área de Paisagem Protegida, para assim poder(em) incorporar paisagens de valor reconhecido e de forte inter-relação entre a sua natureza biofísica e as práticas 
culturais e usos tradicionais da comunidade local. Trata-se, assim, de um outro ciclo ou geração de unidades de geo-conservação (Figura 3).

Figura 2 - Municípios com Áreas Classificadas (Parque Natural).

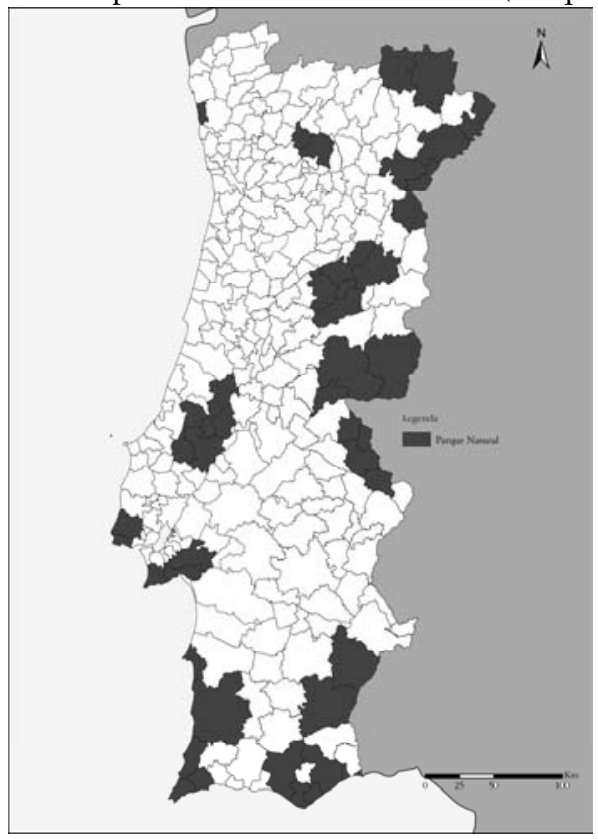

Figura 3 - Municípios com Áreas Classificadas (Paisagem Protegida).

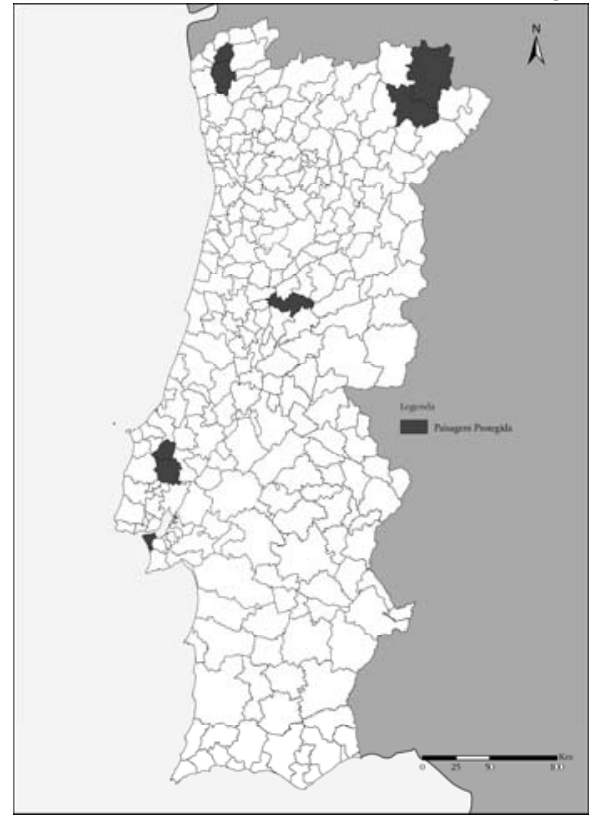


Figura 4 - Municípios com Áreas Classificadas (Área/Reserva Botânica).

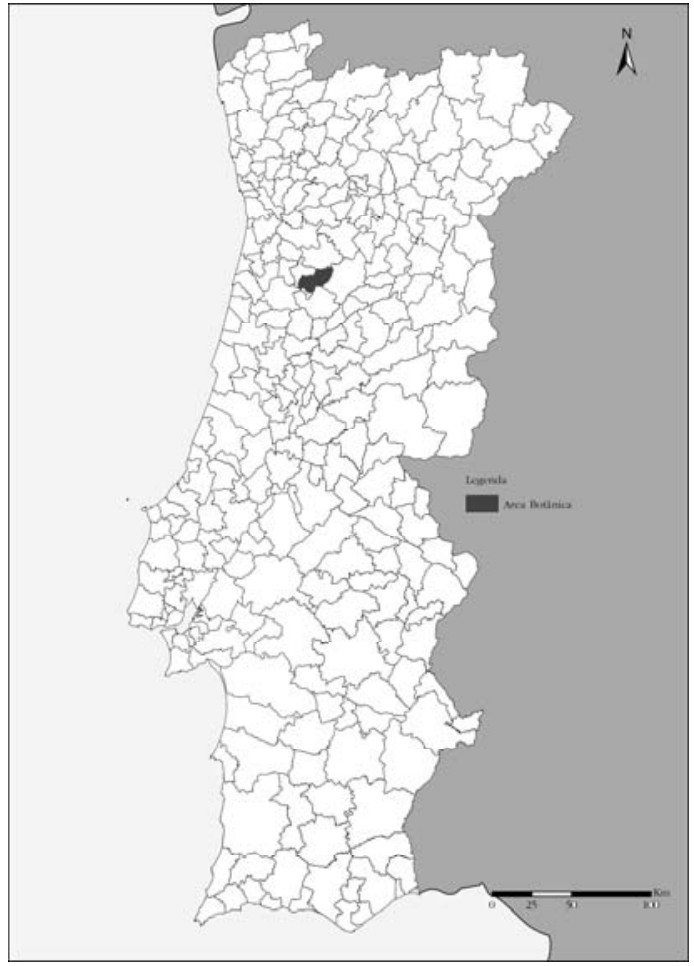

Como atitude técnica qualificada a geo-conservação é um caminho viável para dotar o(s) território(s) de novos quadros de relação das actividades humanas com o seu respectivo ambiente, pelo que esta acção deve aqui ser entendida e associada à opção tomada perante o futuro desejado, que o mesmo é relevar a ideia de J. Falk, a «caminhos que nos obrigam a olhar com maior sensibilidade para o ambiente, que nos levam a usar os recursos do planeta como finitos e o ambiente como um bem que não tem a capacidade ilimitada de absorver os danos que lhe causamos» (Melo \& Pimenta 1993, p. 39).

Com a publicaçáo da Lei de Bases do Ambiente (Lei no 11/87) e do Decreto-Lei no 19/93, de 23 de Janeiro, altera-se de novo o quadro jurídico das APs, já que tais diplomas fundamentam e regulam o quadro sistémico e organizacional definido - de Rede Nacional de Áreas Protegidas (RNAP). Para além disso contempla três aspectos novos, especificamente: a criação da figura de Monumento Natural, em vez da manutenção da designação vigente de Lugar/Sítio/Conjunto/Objecto Classificado; a distinção de nível ou escala de valor da figura de Paisagem Protegida, ao consagrar a possibilidade de serem criadas áreas ou unidades de interesse regional/local, de gestão partilhada entre o ICN nacional e as Autarquias/Municípios; por último, a possibilidade de serem criadas áreas privadas de conservaçáo ambiental, a serem propostas por proprietários de terrenos, que encerram ou detenham casos de recursos naturais para fins de preservaçáo da sua biodiversidade, e que nessa situação serão designados por Sítios de Interesse Biológico.

Em quadro de dados (tabela I) regista-se o conjunto de áreas protegidas, por períodos, por tipo de estatuto, bem como a sua dimensão. 
Tabela I - Áreas Protegidas Instituídas em Portugal Continental (1971-2005)

\begin{tabular}{|l|c|c|c|c|c|c|c|c|}
\hline $\begin{array}{l}\text { Categoria } \\
\text { De AP }\end{array}$ & $\begin{array}{l}\text { Área } \\
\text { Km2 }\end{array}$ & $\begin{array}{l}1971- \\
1975\end{array}$ & $\begin{array}{l}1976- \\
1980\end{array}$ & $\begin{array}{l}1981- \\
1985\end{array}$ & $\begin{array}{l}1986- \\
1990\end{array}$ & $\begin{array}{l}1991- \\
1995\end{array}$ & $\begin{array}{l}1996- \\
2000\end{array}$ & $\begin{array}{l}20001- \\
2007\end{array}$ \\
\hline $\begin{array}{l}\text { Parque } \\
\text { Nacional }\end{array}$ & 710 & 1 &.. &.. &.. &.. &.. &.. \\
\hline $\begin{array}{l}\text { Reserva } \\
\text { Natural }\end{array}$ & 692 & 3 & 5 & 2 & 1 &.. & 1 &.. \\
\hline $\begin{array}{l}\text { Paisagem } \\
\text { Protegida }\end{array}$ & 126 &.. &.. & 3 & 2 &.. & $(4)$ &.. \\
\hline $\begin{array}{l}\text { Parque } \\
\text { Natural }\end{array}$ & 5502 &.. & 4 & 1 & $1^{*}$ & $3^{* *}$ & 3 & $1^{* * *}$ \\
\hline $\begin{array}{l}\text { Lugar/Sítio } \\
\text { Classificado }\end{array}$ & $23 ?$ &.. & 5 &.. &.. & 5 &.. &.. \\
\hline $\begin{array}{l}\text { Monumento } \\
\text { Natural }\end{array}$ & $1,5 ?$ &.. &.. &.. &.. &.. & 5 & 1 \\
\hline
\end{tabular}

${ }^{*}$ Era anteriormente Reserva Natural (Ria Formosa)

**D Duas unidades eram anteriormente Paisagem Protegida (Sintra-Cascais e SW Alentejano e Costa Vicentina)

***Era anteriormente Paisagem Protegida (Litoral de Esposende)

? ( ) São dados estimados, não oficiais, e os espaços protegidos de interesse regional/local, respectivamente.

$\mathrm{O}$ acto classificativo de uma $\mathrm{AP}$ dá-lhe não só uma importância valorativa nacional como também uma dimensão extra-nacional, quando essa classificação tem correspondência com o quadro instituído e convencionado pela União Internacional da Conservação da Natureza (e seus recursos) para as áreas protegidas do mundo.

\section{DINÂMICAS DEMOGRÁFICAS NAS ÁREAS PROTEGIDAS: OS CONTRASTES E AS TENDÊNCIAS}

A População residente nos Municípios com unidades de conservação importantes na RNAP, em 2001 e 2005, no Continente registavam um total de 2603361 habitantes e de 2747290 (estimativa), respectivamente. Por desagregação espacial, em 2001 e segundo as NUTS II, a Região Norte possuía 317950 indivíduos, a Região Centro 819 844, as Regiôes de Lisboa e do Alentejo 1221 967, e a Região do Algarve 243 600. Os municípios constituintes do Portugal protegido possuíam $25,2 \%$ da populaçáo portuguesa. O INE estimava em 2006 que a População residente total no Continente é de 10599095 pessoas (5 129937 são homens e 5469158 são mulheres).

$\mathrm{Na}$ década de noventa a síntese demográfica nacional consubstancia-se no reforço da «atlantização do povoamento», com o crescimento e consolidação da chamada "polpa urbana» litoral, compreendida entre as Cidades-capitais de Viana do Castelo a Setúbal e ao longo do litoral algarvio, enquanto na zona interior e raiana nos surge uma «insularidade urbana» gerada pelas Cidades (médias) aí existentes. No último período inter-censitário, a populaçáo residente cresceu somente 5\% (a que correspondem 488970 indivíduos) e a população estrangeira no país mais que duplica ao representar hoje 2,2\% do total da populaçáo nacional. Em 2001, para um idoso havia quatro indivíduos em idade activa (15-64 anos) e consolida-se o "duplo» envelhecimento da populaçáo (no topo e na base) porque a população idosa ultrapassou pela primeira vez a população de jovens e isto nos primeiros anos deste novo século. A esta evoluçáo demográfica associam-se progressos relevantes no acesso da população aos vários níveis de ensino pós-secundário, já que du- 
plica a proporção demográfica com ensino superior; ocorre uma cobertura quase total dos alojamentos com infra-estrutruras básicas e um investimento significativo e crescente em serviços de base ambiental.

As AP's integradas em municípios metropolitanos do Porto e Lisboa, bem como em Cidades-capitais de distrito e/ou Cidades médias apresentam dinâmicas demográficas positivas, já que a urbanidade é de proximidade e esta gera atracão de população e de actividades. $\mathrm{E}$ isto quando se constata que as áreas/unidades classificadas com mais baixos índices de idadismo estão integradas em municípios da zona litoral, em espaços económico-sociais dinâmicos e/ou territórios densamente povoados e, consequentemente, na vizinhança de cidades importantes do sistema urbano nacional. Por oposição a esta realidade temos os casos de territórios do interior serrano e sem proximidade a redes urbanas importantes, pelo que, entre 1991-2001, as unidades de conservação inseridas em municípios que perderam população foram as seguintes (Tabela II): Peneda-Gerês; Montesinho, Douro Internacional, Tejo Internacional, Serra de S. Mamede, Vale do Guadiana; Malcata e do Paúl de Boquilobo; e Serra do Açor.

Tabela II - Evolução da População residente nos Municípios com AP’s entre 1991-2001

\begin{tabular}{|l|c|c|c|}
\hline \multicolumn{1}{|c|}{ 2007, ÁREA PROTEGIDA (categoria) } & $\begin{array}{c}\text { No Pop. } \\
\text { residente } \\
1991\end{array}$ & $\begin{array}{c}\text { No Pop. } \\
\text { residente } \\
2001\end{array}$ & $\begin{array}{c}2001-1991 \\
(\%)\end{array}$ \\
\hline Peneda-Gerês (Parque Nacional) & 76006 & 68778 & $-9,5 \%$ \\
\hline Serra do Alváo (Parque Natural) & 55818 & 58530 & $+4,9 \%$ \\
\hline Serra de Montesinho (Par Natural) & 45782 & 45396 & $-0,8 \%$ \\
\hline Douro Internacional (Par Natural) & 44873 & 40508 & $-9,7 \%$ \\
\hline Litoral Norte (Parque Natural) & 30101 & 33325 & $+10,7 \%$ \\
\hline Serra da Estrela (Parque Natural) & 153603 & 155562 & $+1,3 \%$ \\
\hline Serras de Aire e Cande (P Natural) & 155562 & 262044 & $+3,7 \%$ \\
\hline Tejo Internacional (Parq Natural) & 72900 & 71465 & $-2,0 \%$ \\
\hline Serra do Açor (Paisag Protegida) & 71465 & 13623 & $-2,2 \%$ \\
\hline Dunas de S. Jacinto (Res Natural) & 66444 & 73335 & $+10,4 \%$ \\
\hline Paúl de Arzila (Reserva Natural) & 178454 & 189261 & $+6,1 \%$ \\
\hline Serra da Malcata (Reserva Natural) & 25034 & 21529 & $-14,0 \%$ \\
\hline Ilha Berlenga (Reserva Natural) & 25880 & 27315 & $+5,5 \%$ \\
\hline Sintra-Cascais (Parque Natural) & 414245 & 534432 & $+29,0 \%$ \\
\hline Estuário do Tejo (Reserva Natural) & 132075 & 159175 & $+20,5 \%$ \\
\hline Serra de S. Mamede (Parq Natural) & 38352 & 37270 & $-2,8 \%$ \\
\hline Vale de Guadiana (Parq Natural) & 27720 & 25435 & $-8,2 \%$ \\
\hline Serra da Arrábida (Parque Natural) & 174737 & 204854 & $+17,2 \%$ \\
\hline SW Alentej e C Vicentina (P Natur) & 71059 & 75718 & $+6,6 \%$ \\
\hline Arriba Fóssil C Caparica (P Proteg) & 179029 & 198392 & $+10,8 \%$ \\
\hline Paúl de Boquilobo (Reser Natural) & 6072 & 5710 & $-6,0 \%$ \\
\hline Estuário do Sado (Reserva Natural) & 175770 & 196475 & $+11,8 \%$ \\
\hline Lagoas da Sancha S. André (R Nat) & 43822 & 44682 & $+2,05 \%$ \\
\hline Ria Formosa (Parque Natural) & 173415 & 200972 & $+15,9 \%$ \\
\hline Castro Marim V.R.S.António (RNat) & 21203 & 24549 & $+15,8 \%$ \\
\hline
\end{tabular}

Fonte: Portugal-INE 1991 e 2001, Censos da Populaçáo. 
As unidades de conservação que qualificam este Portugal Protegido (Figuras 1 a 4) são internamente espaços demográficos estáveis ou regulados mas na sua faixa externa confinam com territórios demograficamente distintos em termos de evolução e de umdança económico-social, já que em alguns municípios do litoral português as áreas protegidas constituíram um instrumento técnico-legal de ordenamento e gestão de recursos naturais ao contrariar a intensificaçáo construtiva de certas parcelas do território e mesmo de obstar certas pressóes urbanísticas ou propostas de transformaçáo desapropriada e desaconselhável do uso do solo primário.

\section{SustentabilidAdE DO AMBIENTE E DO DESENVOLVIMENTO. CONTRIBUTO(S) PARA UMA ANÁLISE PROSPECTIVA.}

Desde a década de noventa e função do envolvimento internacional do País, que os domínios do Ambiente e do Desenvolvimento se cruzam e se intenta compatibilizar nos seus propósitos públicos, de interesse comum e objectivos de governança. Esta realidade pode ser comprovada pela implementaçáo da rede Natura 2000, através da respectiva lista nacional de sítios classificados como «zonas de protecção especial» e de «sítios de importância para a conservação", em 1999, e também a definição de uma Estratégia Nacional da Conservação da Natureza e da Biodiversidade (ENCNB), em 2001. Somente em 2007 Portugal se compromete em adoptar uma Estratégia Nacional de Desenvolvimento Sustentável (ENDS) e o seu respectivo "plano de implementação» até 2015.

Neste quadro se deve inscrever um outro processo/instrumento, no caso, a proposta de um «sistema de indicadores de desenvolvimento sustentável», em 2000, para a melhoria da gestão do desempenho ambiental, económico, social e institucional do país. Tal sistema foi, em 2007, revisto e adoptado, com vinte e sete áreas temáticas e cento e dezoito indicadores; em 2009, estabelece-se um conjunto de trinta indicadores-chave com relação aos objectivos da ENDS.

A relação do Ambiente com o Desenvolvimento foi sempre problemática porque se trata de um conhecimento complexo e multidimensional, por vezes de gestáo difícil, por vezes inconciliável, e que exige também uma organização sistémica. Ora isto coloca em questão a pretensa sustentabilidade destas duas áreas porquanto a incerteza é o presente e o próximo futuro do nosso quadro de desenvolvimento. Um instrumento aqui aplicável é o documento estratégico europeu "Travar a Perda de Biodiversidade até 2010 - e Mais Além. Preservar os serviços ecossistémicos para o bem-estar humano», onde se traçam metas de actuação conservacionista e de gestão de recursos naturais que impóem regulação dos sistemas e respectivos processos económicos.

Nesta situação a reflexão pode resumir-se a estas interrogaçóes: que entrosamento de medidas e acçóes para os dois territórios - o Portugal protegido e o Portugal não protegido?; e que integração de estratégias portuguesas para «suster a perda de biodiversidade» mas também a perda de populaçáo rural e o quadro próximo e essencial de crescimento da economia portuguesa em período de crise (estrutural do país e da própria globalização)?

Quanto à primeira questão a própria ENDS (2007-2015) corporiza a integração e a transversalidade do ambiente nas várias áreas sectoriais da governação pública, bem como se encontra em processo inicial e expectável a transição da RNAP para a Rede Fundamental da Conservação da Natureza e da Biodiversidade, em termos de planeamento e 
gestão territorial. Os progressos serão, p. ex., as dinâmicas funcionais ou as mais-valias resultantes das medidas inerentes às nove regiốes actuais de "Intervençóes Territoriais Integradas» (ITI), bem como outras acçóes de qualificação de recursos da nossa biodiversidade. Quanto à segunda questão uma das respostas terá de ser encontrada entre os dois lados da mesma realidade, ou seja, pela matriz que produz e pelo conjunto que consome o sistema Território. Parece ser imperativo uma governança para o desenvolvimento sustentável, que fomente e/ou incremente políticas endógenas - de base produtiva nacional, - a partir dos recursos da Paisagem (redescobrir os bioprodutos ou os novos ecorecursos da modernidade gerados pela aliança da tradição com a inovação); por outro lado, isto não pode ser espontâneo nem deixado a um mercado ilimitado, pelo que, devese regular e/ou controlar os padróes de uso e consumo de recursos ambientais não eficientes e associados a um mercado de bens incorporando externalidades significativas.

Numa relação de conjunto e de pretensa conciliação do Ambiente com o Desenvolvimento tomo como referência maior o actual Plano Nacional de Barragens com Elevado Potencial Hidroeléctrico (PNBEPH), em especial os projectos programados para as bacias hidrográficas com biodiversidade natural mais relevante, com conteúdo paisagístico rústico e de maior compromisso entre a sua Natureza e o Homem e onde as condiçóes de qualidade ambiental são elevadas. O programa contempla dez intervençóes e está em implementaçáo mas o modelo adoptado é questionável (de infra-estrutura(s) pesada e de grande dimensão) porquanto vai criar alteraçóes no próprio sistema natural da bacia e diminuir a nossa capacidade de cumprir as tais metas de «travar a perda da biodiversidade» e também póe em causa os compromissos inerentes à aplicação da Directiva Habitates e o "entrosamento de políticas sectoriais para o desenvolvimento», a curto e médio-prazo. Isto porque cerca de metade desses projectos hidroeléctricos comportam impactos irreparáveis no sistema «bio e ecocultural» do Território Continental português. E porque a produção e o consumo deste tipo de energia estão espacialmente distantes e numa análise de custobenefício quem mais perde com este processo são os territórios rurais e o património natural nacional.

De momento, surgem referências técnicas e matérias de reflexão, por parte de organismos independentes e/ou de organizações não-governamentais, sobre a qualidade do investimento e a natureza ou dimensão de projectos públicos ancorados em quadros estratégicos de aproveitamento de energias limpas e renováveis.

\section{Conclusão}

$\mathrm{Na}$ década que estamos a viver assistimos a mudança de paradigma no sistema produçãoconsumo do Território nacional. Mas também na forma de o povoarmos, de o usarmos e de o fruirmos. As dinâmicas demográficas, e o quadro territorial em que elas se geram, ajudam a essa descoberta e a sinalizar algumas tendências de evolução. Se tem existência um Portugal Protegido, o qual ultrapassa a tradicional assimetria e visão dicotómica Litoral-Interior, as dinâmicas demográficas dos municípios com áreas protegidas classificadas demonstram o papel e a relevância da rede ou sistema urbano português, bem como o potencial de funções induzido por programas sectoriais (qualificados de integrados) e pela urbanidade em áreas demograficamente fracas ou em perda. 


\section{REFERÊNCIAS BIBLIOGRÁFICAS}

Alves, Rui M. Amaro 2007, Politicas de Planeamento e Ordenamento do Território no Estado Português, Fund. Calouste Gulbenkian e FCT, Lisboa.

Lopes, José da Cruz 2003, Ecodesenvolvimento, Geografia do Ambiente e Turismo, ed. Autor e ESTG-IPVC, Viana do Castelo.

Pimenta, C. e Melo, J. Joanaz de 1993, Ecologia e Ambiente, Difusão Cultural, Lisboa.

Portugal-INE 1994 e 2003, Censos da População, Imprensa Nacional-Casa da Moeda, Lisboa.

Santos, Filipe D. 2007, Que Futuro? Ciência, Tecnologia, Desenvolvimento e Ambiente, Gradiva e Fund. Calouste Gulbenkian, Lisboa.

\section{FONTES ELECTRÓNICAS}

Agência Portuguesa do Ambiente [Online] Disponível em:

http://www.apambiente.pt/politicasambiente/DesenvolvimentoSustentavel/Documents/ENDS\%202015\%20-

\%202\%20\%C2\%BA\%20Relat\%C3\%B3rio\%20Intercalar\%20de\%20Execu\%C3\%A7\%C3\%A3o.pdf

http://www.apambiente.pt/politicasambiente/DesenvolvimentoSustentavel/Documents/ENDS\%202015\%20-

\%201\%20\%C2\%BA\%20Relat\%C3\%B3rio\%20Bienal\%20de\%20Execu\%C3\%A7\%C3\%A3o.pdf

Comunidade Europeia/União Europeia [Online] Disponível em:

http://ec.europa.eu/environment/nature/natura2000/management/best_practice_en.htm

http://ec.europa.eu/environment/networks/index_en.htm

http://www.nationmaster.com/country/po-portugal/env-environment

Instituto da Conservaçáo da Natureza e da Biodiversidade [Online\} Disponível em:

http://portal.icnb.pt/ICNPortal/vPT2007/O+ICNB/Documentos+de+referência/Estratégia+Nacional+da+Cons ervaçăo+da+Natureza+e+da+Biodiversidade/

http://portal.icnb.pt/ICNPortal/vPT2007/O+ICNB/Ordenamento+e+Gestão/Plano+Sectorial+da+Rede+Natur a $+2000 /$ Plano+Sectorial + da + Rede+Natura +2000 htm

http://portal.icnb.pt/NR/rdonlyres/CF2373DD-455E-4312-A9C7-

847BCA22E84A/6210/ComunicacaoBiodiversidade.pdf

Portal do Governo [Online] Disponível em:

http://www.portugal.gov.pt/pt/Documentos/Governo/MAOTDR/PNBEPH_Resumo.pdf

http://www.portugal.gov.pt/pt/Documentos/Governo/MAOTDR/Plano_Barragens_Apres_MAOTDR.pdf 